\title{
Aspectos da produção leiteira em pequenas unidades de produção familiar no assentamento Mutirão Eldorado em Seropédica, Rio de Janeiro
}

\section{Aspects of the livestock milk in small units of family productions in the establishment Eldorado in Seropédica, Rio de Janeiro}

\author{
Jonathan Johanz Quiroz Zegarra, ${ }^{*}$ Bruno César Ribeiro da Silva Oliveira, ${ }^{* *}$ Rosângela Antunes da Siva, ${ }^{* * *}$ \\ Olavo Brandão Carneiro, ${ }^{* * *}$ Rita de Cássia Campbell Machado Botteon, ${ }^{* * * *}$ Paulo de Tarso Landgraf Botteon, ${ }^{* * * * *}$
}

\begin{abstract}
Resumo
A agricultura familiar é uma atividade de grande importância econômica e social. Em geral, as pequenas unidades agrícolas caracterizam-se pela diversidade dos sistemas de produção. Ultimamente a produção de leite vem sendo apontada como alternativa viável para melhoria e manutenção das condições financeiras da propriedade familiar. De uma relação de famílias que compõem o Assentamento Mutirão Eldorado em Seropédica - RJ, foram identificadas aquelas que desempenham entre outras atividades a pecuária, constatando-se que a maioria dos produtores relatavam a necessidade de adoção de medidas que resultassem na melhoria da qualidade dos produtos e aumento da produtividade. A atividade pecuária para fins de consumo e/ou comercialização foi confirmada em 12 lotes. Todavia, um dos criadores não manifestou interesse em participar do estudo. As características dos rebanhos foram avaliadas individualmente, mediante entrevista, exame clínico e exames complementares. Como medidas profiláticas foram relatadas a vacinação e o controle de ectoparasitos. Em todos os lotes estudados o gado era mestiço, criado de forma extensiva, alimentado basicamente a pasto e ordenhado de forma manual com bezerro ao pé. Nenhum criador adotava medidas preventivas ou controle de mastite que foi identificada em $39,2 \%$ das vacas em lactação. Do total de vacas examinadas, 32\% estavam prenhes e $55 \%$ estavam em lactação, com uma média de produção de 2,5 litros/vaca/dia. Na opinião dos criadores, a falta de financiamento, assistência técnica e a qualidade da água dificultam a produção.
\end{abstract}

Palavras-chave: agricultura familiar, assentamentos rurais, pecuária leiteira, produção, criação.

\begin{abstract}
The family agriculture is an activity great economical and social importance. In general, small agriculture units are characterized by the diversity of systems. Lately it comes if highlighting the milk production that has been pointed as a viable alternative for improvement and maintenance of the financial conditions of the family property. Starting from a relationship of the families that composed the rural community Eldorado in Seropédica - RJ, were identified those that carry out among other activities, the production of milk and flowed and need of adoption of measures that resulted in improvement of the quality of the products. Milk or cheese production for ends of consumption and/our commercialization was performed in 12 properties, however one farmer did not show interest in take part in the research. Sanitary conditions were evaluated through clinical examination and complementary tests. Prophylactic measures of disease control were related to vaccination and parasite control. In all visited properties, crossbred cattle, extensive culture, milk manual, occasional food supplementation, no measures of mastitis control, identification in $32,9 \%$ of cattle in lactation. The total of cows examined $32 \%$ was pregnant and $55 \%$ were in lactation. The average of milk production was 2,5l/cow/day. For farmers, factors that contribute to the difficulties in production were absence of financial support, technical assistance and quality of the water.
\end{abstract}

Keywords: family agriculture, rural establishments, livestock milk pan, production, breeding.

\section{Introdução}

No contexto mundial, o Brasil é um dos maiores produtores de leite, ocupando o sexto lugar. O leite, além da sua importância nutricional, desempenha um relevante papel social, principalmente na geração de emprego e renda. A agricultura familiar, constituída por mini e pequenos agricultores, representa $77 \%$ dos produtores rurais no Brasil, detém $30,5 \%$ da área total dos estabelecimentos rurais e produz $38 \%$ do Valor Bruto da Produção da Agropecuária

\footnotetext{
* $\quad$ Discente de Mestrado em Medicina Veterinária da UFRuralRJ.

** Discente do curso de Medicina Veterinária - UFRuralRJ - Bolsista de Iniciação Científica PIBIC - CNPq

*** Discente do curso de Medicina Veterinária - UFRuralRJ - Bolsista de Iniciação Científica FAPERJ.

**** Discente do curso de Medicina Veterinária - UFRuralRJ.

***** Docente do Departamento de Medicina e Cirurgia Veterinária - Instituto de Veterinária - UFRuralRJ.
} 
Nacional de acordo com dados do IBGE (2004). Segundo o Instituto Nacional de Colonização e Reforma agrária (INCRA) e do Fundo das Nações Unidas para a Agricultura e Alimentação (FAO) são 13,8 milhões de pessoas em cerca de 4,1 milhões de estabelecimentos familiares, o que corresponde a $18 \%$ do total da população economicamente ativa do país.

A agricultura familiar é uma forma de produção em que o núcleo de decisões, gerência, trabalho e capital é controlado pela família. Em geral, são agricultores com baixo nível de escolaridade que diversificam os produtos cultivados para diluir custos, aumentar a renda e aproveitar as oportunidades de oferta ambiental e disponibilidade de mão-de-obra (Abramovay et al., 1996). Apesar do predomínio das culturas anuais, a grande maioria das famílias de pequenos produtores rurais mantém, em seus estabelecimentos, animais para produção de leite. Atualmente, cerca de 1,5 milhão de agricultores familiares têm atividades de pecuária de leite (Pronaf, 2007). É fenômeno recente a transformação dessa atividade de subsistência em atividade comercial, como forma de diversificar a renda e garantir o acesso a gêneros não produzidos nos estabelecimentos de agricultura familiar (Escosteguy et al., 1993). A bovinocultura leiteira, devido a sua capacidade de geração de emprego e distribuição de renda, tem sido apontada como alternativa viável para melhoria das condições financeiras de agricultores familiares em assentamentos de reforma agrária (Abramovay, 1997).

Evidentemente, boa parte dos milhões de propriedades familiares existentes no Brasil apresenta problemas como a falta de capacidade de autofinanciamento, falta de capacitação dos recursos humanos e, principalmente, não possuem informações de tecnologias que reduzam seus custos de produção. Além disso, os pequenos produtores em geral têm dificuldades para se associar de forma a favorecer a comercialização de seus produtos (Roldão et al., 2002). Atualmente, trabalha-se com a hipótese de que em poucos anos, mantido o ritmo de mudanças nos componentes da indústria e consumo da cadeia do leite, o destino da produção familiar é desaparecer. Considera-se que os empreendimentos familiares de produção de leite somente sobreviverão se tiverem economias de escala, oriundas de tecnologias adequadas de alimentação, manejo do rebanho, de gado de genética mais apurada e gerência profissional das atividades (Schneider, 2003). Os desafios a serem vencidos são inúmeros. As instituições de pesquisa e desenvolvimento devem participar da revisão desse quadro. Para que o agricultor familiar possa superar as limitações dos sistemas de produção atualmente em uso, atender às exigências do mercado consumidor, obter maior renda, preservar os recursos naturais e melhorar sua condição de vida, a pesquisa agropecuária exerce papel fundamental.

Através de Projeto de Extensão, obteve-se a informação da existência de 32 famílias no Assentamento Mutirão Eldorado em Seropédica - RJ, exercendo a atividade pecuária e a produção de leite e/ou queijo para fins de consumo ou comercialização, e que a maioria dos produtores relatava a má qualidade dos produtos. Nesse sentido, decidiu-se atuar junto a esses agricultores, com a finalidade de identificar as falhas no processo de produção e a possibilidade de adoção de medidas que pudessem contribuir para a melhoria da qualidade do produto e aumento da produtividade.

\section{Material e métodos}

A partir da relação de famílias que compõem o Assentamento Mutirão Eldorado, no Município de Seropédica - Rio de Janeiro, foram identificadas por meio de Projeto de extensão (Instituto de Ciências Humanas e Sociais - Departamento de Letras e Ciências Sociais/Instituto de Veterinária - Departamento de Medicina e Cirurgia Veterinária/UFRRJ), as 32 famílias que exerciam a atividade pecuária. Através de entrevista ao titular do lote, obtiveram-se informações quanto ao número de animais, raça, manejo nutricional, higiênico e sanitário, causas de mortalidade, formas de identificação, prevenção e tratamento de doenças, finalidade da produção e assistência veterinária, entre outras. Os dados foram anotados em formulários individuais. Cada entrevista foi seguida de visita às instalações para observação das condições de criação dos animais. Para a análise das informações coletadas através da entrevista, construiu-se um banco de dados. Procedeu-se então à descrição dos dados para extrair as conclusões do estudo exploratório.

Entre os 32 assentados identificados inicialmente como pecuaristas produtores de leite, a atividade pecuária para fins de consumo e comercialização foi confirmada em 12 lotes; todavia, um dos criadores não manifestou interesse em participar do estudo, ficando assim o número de unidades de produção reduzido a 11. Neste momento, os objetivos deste trabalho foram a identificação dos agricultores que exerciam a atividade pecuária e o cadastramento das unidades de produção a serem estudas, bem como identificar as condições de criação e ocorrência de enfermidades segundo a percepção dos criadores.

Em visitas subseqüentes mediante o consentimento dos proprietários e sempre que possível na presença destes, as características sanitárias dos rebanhos de cada unidade de produção foram avaliadas individualmente, mediante exame clínico conduzido no sentido de identificar sinais ou sintomas de enfermidades infecciosas, parasitárias, metabólicas e/ou nutricionais. Dos animais que ao exame clínico apresentaram sinais de enfermidades, foram obtidas amostras de material para exames complementares, segundo a indicação de cada caso.

No início da ordenha foram realizados os testes da caneca de fundo preto e o California Mastitis Test (CMT), para detecção dos quartos mamários com mastite clínica e subclínica, respectivamente, em todas as vacas ordenhadas, ao mesmo tempo em que se realizou o diagnóstico de gestação através de palpação retal.

Ao final da ordenha, dos quartos mamários com alterações clínicas, foram obtidas amostras de leite em frascos estéreis para isolamento e identificação de agentes microbianos.

Inicialmente, pretendia-se obter amostras de soro sanguíneo de todos os bovinos, para detecção de anticorpos contra brucelose e, paralelamente, os rebanhos seriam avaliados para diagnóstico de tuberculose através de testes intradérmicos. Contudo, diante do grau de esclarecimento dos produtores quanto à necessidade de realização destes exames e da relutância dos mesmos, optou-se pela nãorealização dos exames, preferindo-se atuar de maneira educativa de forma a esclarecer sobre os riscos de transmissão através do leite e da importância da identificação da ocorrência de enfermidades transmissíveis comuns entre o homem e os animais. 
Os resultados foram fornecidos aos produtores em reunião na associação, sem nenhum custo para os mesmos, e medidas de melhoria das condições de criação e produção foram avaliadas individualmente em cada lote estudado.

\section{Resultados e discussão}

Em todas as ocasiões, os membros da equipe foram recebidos de forma cordial e os assentados demonstraram, em sua maioria, interesse na melhoria da qualidade da produção.

Dos 12 lotes em que foi confirmada a atividade pecuária, quatro $(36,36 \%)$ entre os meses de abril e setembro de 2003, estavam produzindo leite apenas para consumo, quatro $(36,36 \%)$ produziam leite e fabricavam queijo e dois $(18,18 \%)$ utilizavam o leite produzido para a comercialização com entrega em domicílio. Um dos criadores (9,09\%) informou que se dedicava à venda de leite e queijo, mas no momento todo o leite produzido era destinado à alimentação dos bezerros e um assentado (9,09\%) não manifestou interesse em participar da pesquisa e não permitiu o exame clínico dos seus animais.

A utilização de vacinas foi relatada por $90,9 \%$ dos entrevistados. Somente dois criadores (18,2\%) informaram a utilização de vacina contra raiva e nenhum informou utilizar vacina contra brucelose. A única vacina utilizada de forma sistemática pelos criadores (10/11) foi contra a febre aftosa e, neste caso, as vacinações eram realizadas durante as campanhas por ação das prefeituras de Seropédica e/ou Itaguaí e eram aplicadas por técnicos da prefeitura ou por eles mesmos mediante o fornecimento das doses. Em duas unidades de produção (18,2\%), obteve-se a informação de que a vacina contra aftosa não foi aplicada naquele ano porque a prefeitura não enviou o produto durante a última campanha. Em estudo sobre o perfil produtivo-sanitário de bovinos no estado da Paraíba (Leite et al., 2004) obtiveram a informação de que a grande maioria das propriedades vacinava seus rebanhos contra febre aftosa e raiva $(92,75 \%)$, enquanto que o percentual de vacinação para brucelose $(7,24 \%, 5 / 69)$ a exemplo do presente estudo, foi baixo. Percentuais mais elevados de utilização de vacinas contra febre aftosa comparativamente às demais vacinas foram registrados por Cruz et al. (1981), Aguiar (1984), Viana (1987), Moreira (1988), Prado et al. (1997), Rocha e Gomes (1999) e Botteon et al. (2002) em outras regiões. Essa baixa cobertura vacinal contra brucelose tornase mais crítica quando se considera que o Programa Nacional de Controle e Erradicação de Tuberculose e Brucelose (BRASIL, 2001) propõe que a vacinação esteja implantada em todos os estados do país até o final de 2003, momento em que era realizada esta pesquisa.

Unanimidade entre os criadores foi a constatação de que a vacinação contra aftosa resulta em desconforto ao animal e formação de "caroços" no local da aplicação. Ao serem questionados sobre as formas de conservação e aplicação das vacinas, obteve-se como informações mais freqüentes a conservação em caixas de isopor com gelo, utilização de pistolas e agulhas não individuais sem higienização do local de aplicação, o que pode contribuir para a formação de edemas e abscessos no local de aplicação.

O controle de ectoparasitos como carrapatos e bernes, em todos os lotes estudados foi informado como ocasional, mediante a constatação de animais altamente parasitados. Como produtos utilizados para controle de carrapatos, a maioria dos entrevistados $(54,5 \%)$ informou a Ivermectina (54,5\%) em aplicações por via intramuscular ou produtos como Amitraz (27,3\%) e Piretróides (18,2\%) em aplicação por aspersão, geralmente com a utilização de bombas costais manuais. Para controle de bernes, o produto mais utilizado foi o óleo queimado em associação com Neguvon e Ivermectina que também era utilizada para controle de endoparasitos pela maioria $(63,6 \%)$ dos entrevistados. A aplicação de Ivermectina em vacas em lactação e utilização do leite para consumo ou comercialização durante o período de carência não foram relatados, o que sugere o conhecimento por parte dos criadores dos riscos da presença de resíduos no leite e respeito às normas ou a omissão do fato. O Amitraz, a Cipermetrina e as Avermectinas foram as bases farmacológicas dos produtos mais citados em estudo recente (Rocha et al., 2006) e no passado (Leite, 1988; Furlong e Martins, 2000) para o estado de MG. A utilização de bomba costal para aplicação de carrapaticidas em $80 \%$ das propriedades foi relatada por Rocha et al., (2006), e relacionada com a ineficiência do controle parasitário e causa provável de resistência principalmente pelo grande esforço despendido nessa tarefa.

Produtores com pouca instrução e fazendas com baixa produção e produtividade demonstraram não ter o conhecimento necessário à melhoria do controle dos carrapatos e a repercussão econômica por ele causada (Rocha, 1995). Em estudo recente Rocha et al. (2006) constataram a aplicação de carrapaticidas em intervalos de 15 a 45 dias e em $64 \%$ das propriedades o que determinava o momento do tratamento era a infestação de carrapatos. Segundo Leite e Rocha (1999), a aplicação de acaricidas pelo grau de infestação é muito subjetiva, pois a quantidade limitante de carrapatos depende de interpretação pessoal de cada proprietário e predispõe ao desenvolvimento de resistência.

No presente estudo, os critérios adotados para utilização de produtos carrapaticidas não seguiram parâmetros técnicos. Alta infestação dos animais foi observada em oito $(72,7 \%)$ das 11 propriedades estudadas, o que provavelmente foi decorrente do uso dos produtos em intervalos irregulares, quantidades insuficientes ou desenvolvimento de resistência. Leite (1988) já alertava para a necessidade de orientações adequadas sobre o fármaco a ser utilizado em cada rebanho, pois, dependendo do manejo e da raça bovina, com o tempo, a constância e o critério desordenado de uso podem provocar falência no controle parasitário.

A utilização de produtos para controle de endoparasitos foi informada como ocasional em todas as unidades de produção, e em geral mediante a constatação da presença de animais magros, com pelagem ruim (pêlos arrepiados) e aspecto debilitado, sendo as Ivermectinas em aplicações parenterais as mais utilizadas $(63,6 \%)$. Observou-se neste estudo, que a escolha do produto recai no fator preço mais acessível e as formas de aplicação preferenciais são aquelas que oferecem maior comodidade como os produtos injetáveis e pulverização. Condição semelhante no que se refere aos critérios para utilização de antiparasitários foi relatada por Leite e Lima (1982), Prado et al. (1997) e Botteon et al. (2002). 
Em relação à mastite, sete entrevistados $(66,6 \%)$ informaram saber identificar mastite através de alterações na glândula mamária (endurecimento, aumento da temperatura e edema) ou nas características do leite ("o leite talha", "fica grosso" ou "sai aguado"). Apesar da maioria ter informado saber reconhecer os sinais clínicos da mastite, todos desconheciam a ocorrência da doença em seus rebanhos, inclusive aqueles em que foram constatados casos clínicos. Prado et al. (1997) relataram que $30 \%$ dos criadores asseguravam não serem capazes de identificar mastite. Botteon et al. (2002) informaram que em $85 \%$ das unidades de produção se identificava mastite por alterações no úbere ou alteração na composição do leite. $\mathrm{Na}$ mesma região do presente estudo, Silva et al. (2004) identificaram elevada incidência de mastite em pequenas unidades de produção e o desconhecimento por parte dos proprietários dos índices de mastite em seus rebanhos, mesmo aqueles que informaram visitas regulares de um médico-veterinário em seus estabelecimentos.

Os procedimentos após identificação de casos de mastite foram variados. Quatro criadores $(36,36 \%)$ informaram a utilização de antibióticos, sendo que apenas um ordenhava as vacas positivas separadamente ou no final da ordenha. Nenhum entrevistado informou solicitar a presença do médico-veterinário, porém reconheceram recorrer a estabelecimentos de venda de produtos agropecuários para solicitar informação sobre tratamento de vacas com mastite e outras enfermidades. Dois entrevistados $(18,2 \%)$ relataram que nunca tiveram casos mastite em seus animais. Os procedimentos relatados divergem da constatação de que todos desconheciam a ocorrência da doença em seus rebanhos. Sugerimos, portanto, que as respostas foram de encontro ao que os pecuaristas imaginavam ser correto, independentemente do procedimento adotado. Prado et al. (1997) relatou que $57 \%$ dos produtores, ao identificar vacas com mastite clínica, realizavam o tratamento imediato, procedendo a ordenha dos animais enfermos separadamente. Estes dados comprovam um melhor conhecimento por parte dos criadores estudados por estes autores comparativamente aos que participaram do presente estudo.

Em relação aos animais, o gado em todos os lotes estudados era mestiço, com diferentes graus de sangue zebu, criado de forma extensiva, alimentado basicamente a pasto e ocasionalmente suplementado com cana picada fornecida no cocho em dois lotes (18,2\%). Na maioria dos lotes $(90,9 \%)$, bovinos eram criados junto com eqüinos e além destes, outros animais como porcos e galinhas também eram criados de forma extensiva dividindo espaço e pastagem com o gado. Em avaliação do desempenho técnico e econômico da atividade leiteira em MG (Fassio et al., 2006), foi evidenciado que pequenos e médios produtores utilizam em conformidade com os rebanhos avaliados no presente estudo, animais com grau de sangre inferior a $1 / 2 \mathrm{HZ}$, ou seja, animais rústicos, não especializados para produção leiteira e que por isso apresentam baixa produtividade, além de baixa fertilidade dos rebanhos pesquisados.

O sistema de aleitamento natural (ao pé) foi observado em todas as criações. Em dois lotes (18,2\%), obteve-se a informação de que os bezerros de algumas vacas eram mantidos com as mães durante todo o tempo, sendo a produção de leite destinada exclusivamente à criação destes animais, o que comprova a baixa produtividade do gado. Nos demais lotes, os bezerros eram mantidos com as vacas após a ordenha $(54,5 \%)$ ou durante a tarde e apartados à noite $(27,3 \%)$. Nestes casos, um piquete ou área específica era destinada aos bezerros, sendo os mesmos apenas durante os primeiros dias mantidos em abrigos.

Em todos os lotes realizava-se uma única ordenha diária, de forma manual e com bezerro ao pé, e na maioria $(72,25 \%)$ executada por um único ordenhador, em geral o proprietário do lote ou um familiar (filho ou esposa). O leite acondicionado em baldes ou latões plásticos $(36,4 \%)$ ou de alumínio $(63,6 \%)$ era filtrado com pano $(27,3 \%)$ ou tela plástica $(72,7 \%)$, e resfriado por apenas três $(27,27 \%)$ produtores. Dos sete entrevistados que relataram saber reconhecer casos clínicos de mastite, três $(27,27 \%)$ informaram que misturavam o leite de vacas com mastite ao leite de vacas normais.

Apesar das exigências para que o leite destinado à fabricação de queijos seja submetido à pasteurização ou tratamento térmico equivalente (Brasil, 1974), é intensa a comercialização de queijo fora dessas especificações. Em todas as unidades de produção avaliadas, o queijo era produzido a partir de leite não submetido a tratamento térmico, e conforme já foi dito, apenas três resfriavam o leite, o que representa um risco ao consumidor.

Para verificar a realidade dos casos de mastite clínica e subclínica foram realizados os testes da caneca de fundo preto e CMT em 51 das 58 vacas que compunham o total de vacas em lactação dos rebanhos estudados. Duas vacas recém-paridas e cinco no final de lactação não foram testadas para mastite subclínica e não apresentaram sinais de mastite clínica. A forma clínica e subclínica foram identificadas, respectivamente, em cinco $(9,8 \%)$ e 15 vacas $(29,4 \%)$. O baixo índice de mastite, especialmente a forma clínica, foi atribuído ao manejo extensivo e ordenha com bezerro ao pé, uma vez que a única medida de prevenção informada por quatro produtores $(36,4 \%)$ consistiu em higienização dos tetos com água antes da ordenha. Estes dados diferem dos obtidos em levantamentos regionais que referem que os índices de ocorrência de mastite subclínica são da ordem de $72 \%$ e $17,5 \%$ de mastite clínica, nos estados de Minas Gerais e São Paulo (Costa et al., 2000). Na mesma região do presente estudo, Silva et al. (2004) registraram índices de mastite subclínica variando de 14,3 a $68,6 \%$ entre propriedades com média de $44,7 \%$ e menores índices em unidades de produção que praticavam ordenha manual com bezerro ao pé. Radostitis et al. (2002), Bramley (1992) e Smith (1993) sugerem que ordenha com bezerro ao pé diminui a incidência de mastite, pois leva ao esgotamento completo da glândula mamária, inibindo o desenvolvimento de microrganismos causadores da doença. Contudo, estudos recentes (Costa et al., 1997) sugerem que não há diferença significativa na incidência de mastite, esteja o bezerro mamando ao pé da vaca, ou não.

Em $100 \%$ dos lotes o manejo após a ordenha consistiu em deixar o bezerro fazer o "repasse". Antes da ordenha, a higiene dos tetos com água era realizada por quatro $(36,4 \%)$ criadores, sendo que dois $(18,2 \%)$ secavam com pano depois da lavagem. O mesmo pano era utilizado para todas as vacas e somente um ordenhador lavava as mãos antes de ordenhar. Estes resultados diferem dos encontrados por Prado et al. (1997) e Botteon et al. (2002) onde respectivamente, 30\% e $35 \%$ dos produtores estudados não realizavam nenhuma forma de higiene antes da ordenha. Situação semelhante no 
que se refere à forma de higienização dos tetos antes e após a ordenha e higiene das mãos dos ordenhadores foi relatada por Silva et al. (2004). Apesar do baixo índice de mastite a utilização de um mesmo pano para diferentes vacas pode funcionar como fonte de infecção e na disseminação de microrganismos. Segundo Philpot e Nickerson (1991), uma alternativa para as toalhas de papel que pode ser mais econômica, é o uso de panos individuais desde que estes estejam bem lavados e completamente secos entre ordenhas. Reis et al. (2006) destacam o crescimento no emprego de teste preventivo para mastite (de $24,2 \%$ para $37,6 \%$ ) e higiene do úbere (de $49,3 \%$ para $64,3 \%$ ) em pequenos e médios estabelecimentos paulistas assistidos por um Programa de Melhoria do Sistema Produtivo da Pecuária de Leite implantado pelo SEBRAE - SP. Esses dados reforçam a importância da orientação e assistência técnica para melhoria da qualidade do leite, e como forma de minimizar os efeitos de exclusão das pequenas unidades de produção.

Sabe-se que a higiene dos alimentos exige como pré-requisito o tratamento da água, que é o solvente dos produtos de limpeza e desinfetantes, sendo também o elemento que arrasta a sujeira (ICMSF, 1980). Jesus et al. (1995), em levantamento conduzido no mesmo Assentamento, obtiveram a informação de que a água utilizada para fins domésticos e manejo dos animais em $66,7 \%$ das casas era obtida através de poços, a maioria não manilhados, e apenas 8,3\% cobertos. Em $38,9 \%$ das propriedades, a água vinha de nascentes canalizadas na superfície e apresentava aspecto branco, leitoso com sujidades aparentes. Até o momento da realização do presente estudo, a qualidade da água era problema sério no Assentamento. Na maioria dos lotes $(72,2 \%)$ a água ainda era proveniente de poços artesianos, sem qualquer tratamento e com um agravante, não havia rede de esgoto ou encanamento dos mesmos, sendo os dejetos canalizados em valas a céu aberto, no mesmo ambiente em que pastam animais e circulam os membros das famílias dos assentados e em proximidade com áreas de manipulação do leite e queijo. Este fato contribui para que a higiene geral seja insatisfatória, atuando para o aumento da quantidade de microrganismos presentes no leite e má qualidade dos produtos. A falta de água encanada contribuiu também para a precariedade das condições de higiene no ambiente doméstico e área de manejo dos animais. A raspagem simples foi a forma comum de higiene das instalações, especialmente dos currais e áreas destinadas à ordenha. A maioria informou raspar o curral 2 a 3 vezes por semana e limpeza diária foi relatada em somente em um lote. De forma geral, a higiene foi considerada precária, com grande volume de fezes acumuladas próximo do curral ou residência dos assentados, em pelo menos seis lotes estudados $(50,5 \%)$. Reis et al. (2006) relataram a predominância da limpeza com apenas raspagem após a operação de ordenha (70\%) devido à falta de água corrente em abundância nos estábulos.

Do total de vacas examinadas, 55\% estavam em lactação por períodos que variam de dias (duas vacas recém-paridas) a mais de 12 meses (tempo exato desconhecido pelo entrevistado). Considerando os padrões zootécnicos de referência, os valores ideais seriam 70 a $80 \%$ de vacas em lactação com intervalos entre partos de 12 meses, para garantia da rentabilidade da atividade em propriedades leiteiras. Do ponto de vista reprodutivo, obteve-se a informação de que todos realizam monta natural, sendo comum a utilização de "touro do vizinho" na forma de empréstimo para cobertura das vacas em cio, uma vez que a maioria dos entrevistados $(54,5 \%)$ não possuíam reprodutores entre os animais do rebanho. Constatou-se através de relatos e observações pessoais, que alguns (36\%) utilizam touros da raça nelore adquiridos ainda bezerros, de uma fazenda de gado de corte vizinha ao Assentamento. Entre os assentados é comum a referência ao touro nelore como "muito bom" e nenhum dos entrevistados revelou conhecimento sobre as características de produção relativas à raça, sendo ignorada a possibilidade de que a utilização destes reprodutores pode diminuir a capacidade de produção leiteira dos animais de reposição. $O$ controle de cio não foi relatado nem presenciado em nenhum dos lotes. A informação sobre a idade ao primeiro parto não foi confiável, devido os animais serem de idade avançada, estarem há pouco tempo no lote e/ou não haver nenhum tipo de anotação e controle. Estima-se que o intervalo entre partos esteja em torno de dois anos ou mais. Palpação retal para diagnóstico de gestação revelou um índice de vacas prenhes igual a $32 \%$, sendo a maioria das vacas vazias e paridas há mais de quatro meses. Dentre os problemas reprodutivos relatados destaca-se o prolapso uterino e a repetição de cio. A baixa eficiência reprodutiva deve estar associada a restrições nutricionais, desmame tardio e deficiências no manejo, sobretudo falta de reprodutores e falhas na identificação de cios.

Da mesma forma que o índice reprodutivo, a produtividade entre os lotes foi muito baixa. Em oito lotes (72,8\%) a produção diária foi menor que 15 litros. A média de produção de leite dos rebanhos avaliados foi 2,5 litros por vaca/dia. Todos os entrevistados informaram a dificuldade de produzir leite no inverno, posto que nessa época do ano "a comida é escassa, os animais emagrecem e o leite diminui". Apesar dessa constatação, a maioria (72,7\%) dos entrevistados informou não utilizar campineira ou outra medida para suplementação alimentar no período da seca, contudo, reconheceram a importância desta medida e o interesse em reformar pastos, fazer capineira ou silagem para alimentação do gado no inverno. A produtividade média foi inferior aos 7,7 litros/vaca em lactação relatados por Marques et al., (2002), aos 4,9 litros/ vaca/dia identificados em levantamentos realizados pelo SEBRAE-FAEMG (1996) e aos 5 litros/vaca/ordenha/dia relatados por Reis (1992) entre outros que trabalharam com pequenos produtores. Lima et al. (2002) e Roldão et al. (2002) sugerem a falta de infra-estrutura, de financiamento, de investimentos e de assistência técnica como fatores relacionados com a baixa produtividade em pequenas unidades de produção familiar, o que também é verdade neste assentamento.

Avaliação de dados técnicos e econômicos de 48 propriedades leiteiras distribuídas em cinco regiões de Minas Gerais (Marques et al., 2002) demonstrou que o fornecimento de silagem e ração não foi uma constante entre os produtores de leite analisados; no entanto, o uso de mistura mineral foi comum a todas as propriedades estudadas. No presente estudo, o fornecimento de mistura mineral ou sal grosso foram informados por quatro criadores $(36,4 \%)$, o que não foi constatado em nenhum dos lotes. Como na maioria dos lotes o principal problema informado foi a falta de água acreditamos que a mineralização não é executada e pode contribuir para o 
baixo índice reprodutivo, uma vez que a área estudada apresenta deficiências prováveis de cobre e fósforo, elementos minerais importantes do ponto de vista reprodutivo (Tokarnia et al., 2000). Os indicadores reprodutivos reforçam uma possível carência nutricional, apesar de não ter sido firmado nenhum diagnóstico conclusivo.

A falta de planejamento reprodutivo e sanitário traz implicações diretas na produção e produtividade, já que a reprodução funciona como a alavanca da produção leiteira. Portanto, um incremento na parte reprodutiva levaria ao aumento do número de vacas adultas em lactação e maior rentabilidade. $\mathrm{O}$ melhoramento genético dos rebanhos é essencial para o desenvolvimento da atividade leiteira no Assentamento Eldorado. Contudo, diferentes aspectos precisam ser trabalhados antes que seja possível o investimento em genética dos rebanhos. Problemas como falta de financiamento e assistência técnica dificultam a produção, impedindo o sucesso dos produtores de leite no assentamento estudado. A maioria dos produtores $(63,6 \%)$ informou nunca ter recebido a visita de um médico-veterinário, dois $(18,2 \%)$ receberam a visita de um veterinário particular, um foi visitado por um técnico agrícola ao solicitar financiamento e um já recebeu a visita de um docente da Universidade Rural. Em conformidade com os dados obtidos, Vieira et al. (2002), em estudo sobre a qualidade do leite no município de Urará, estado do Pará, relataram a qualidade genética dos rebanhos, a baixa produtividade, o baixo índice de tecnificação, a falta de financiamento e de assistência técnica como entraves à produção de leite na região estudada.

Ao exame clínico foram identificadas as seguintes enfermidades: artrite séptica em uma bezerra, dermatofilose com diagnóstico confirmado pelo isolamento do agente Dermatophylus congolensis em dois animais adultos e um bezerro, papilomatose em duas vacas, dermatite interdigital em uma vaca, doença da linha branca em uma vaca e fibropapiloma nas tetas de duas das cinco vacas com mastite clínica. Diarréia e onfalite foram identificadas respectivamente em dois e quatro dos 11 bezerros nascidos no período do estudo.

Já na parte final do trabalho, um criador adquiriu um lote de 15 bezerros desmamados para recria, relatando a morte de cinco animais por uma enfermidade "desconhecida". Ao exame clínico dos animais sobreviventes constatou-se intensa infestação por carrapatos além de febre, anemia e baixa condição corporal. Exame hematológico e esfregaço de sangue periférico revelaram a presença de agentes do Complexo Tristeza Parasitária Bovina em cinco animais (62\%). Nesta mesma ocasião, um criador relatou o emagrecimento significativo de uma vaca recém-parida que ao exame clínico apresentou a presença de massa tumoral em vários locais (linfadenomegalia). Avaliação clínica e laboratorial apontaram para a possibilidade de linfossarcoma. Apresentou-se ao proprietário a suspeita clínica e a possibilidade de diagnóstico diferencial com tuberculose, argumentando-se sobre a indicação de sacrifício visando o diagnóstico anátomo-histopatológico. Mediante a condição clínica, o proprietário autorizou o sacrifício que, contudo, não foi realizado devido à venda do animal para o abate. Nesta mesma propriedade, uma novilha prenhe apresentou um quadro agudo de mastite. Neste caso, antes de solicitar a avaliação, o proprietário realizou sucessivas tentativas de tratamento com antibióticos intramamários que não resultaram em remissão do processo. Ao exame clínico notou-se a presença de miíase e fibrosamento do quarto mamário. Obteve-se material para cultura e antibiograma, isolando-se o agente Corynebacterium pyogenes. $O$ animal foi vendido, não sendo conhecida a evolução do quadro.

Procurou-se obter a opinião dos criadores sobre as causas de mortalidade dos animais no assentamento. Picada de cobra e ingestão de plantas tóxicas foram sugeridas por três criadores cada. Outras causas sugeridas foram: "fraqueza" ( 2 criadores), "deficiência de cálcio" (1 criador) e verminose (1). Nenhuma planta tóxica potencialmente causadora de morte súbita em bovinos foi identificada entre as propriedades estudadas.

Após a etapa de levantamento, procedeu-se a uma avaliação dos dados individuais que foram apresentados aos criadores juntamente com as orientações pertinentes em visitas técnicas e reunião na Associação de Moradores. Nesta ocasião obtevese a permissão de quatro criadores para coleta de sangue e realização de testes sorológicos para detecção de anticorpos contra brucelose. Dos soros obtidos de 50 animais com idade acima de 24 meses apenas um apresentou-se reagente ao teste do antígeno acidificado tamponado. Conforme acordado, o proprietário autorizou a marcação do animal e o posterior sacrifício seguindo as normas do Programa Nacional de Controle e Erradicação da Brucelose e Tuberculose Animal instituído em 2001 pelo MAPA.

\section{Conclusões}

Conclui-se pela necessidade de investimentos em infraestrutura e acesso ao crédito, além de orientação técnica visando a melhoria do sistema produtivo. A implementação de um programa sanitário abrangente é importante para o incremento da produção pecuária e garantia de segurança no âmbito da saúde pública.

\section{Auxílio Financeiro}

Fundação de Apoio à Pesquisa Científica e Tecnológica da Universidade Federal Rural do Rio de Janeiro - FAPUR.

\section{Referências}

ABRAMOVAY, R.;VICENTE, M.C.M.;BAPTISTELLAC.S. L.;FRANCISCO, V.L. F. S. Novos dados sobre a estrutura social do desenvolvimento agrícola no Estado de São Paulo. Agricultura em São Paulo, São Paulo, v. 43, n. 2, p. 67-88, 1996.

ABRAMOVAY, R. Uma nova extensão para a agricultura familiar. In: Seminário Nacional de Assistência Técnica e Extensão Rural, Brasília, DF. Anais... Brasília, DF: PNUD, 22 p, 1997.
AGUIAR, B.A. Algumas características de sanidade do rebanho bovino e da estrutura de produção de leite em pequenas unidades produtoras do município de Sete Lagoas - MG. Belo Horizonte: Escola de Veterinaria. UFMG, 35 p. Tese de mestrado em Medicina Veterinária. 1984.

BOTTEON, R.C.C.M., BOTTEON, P.T.L., LÓSS, Z.G. Aspectos sanitários da pecuária leiteira na região do Médio Paraíba - Rio de Janeiro e Minas Gerais. Revista Brasileira de Ciência Veterinária. v. 8, n. 3, p. 141-143, 2002. 
BRAMLEY, A. J. Factors affecting milk quality. In: ANDREWS, A. H.; BLOWEY, R. W.; BOYD, H.; EDDY, R. G. (ed.) Bovine medicine: diseases and husbandry of cattle. Oxford: Blackwell Scientific Publications. p. 291-334, 1992.

BRASIL. Ministério da Agricultura. Departamento de Nacional de Inspeção de Produtos de Origem Animal. Regulamento da Inspeção Industrial e Sanitária de Produtos de Origem Animal (RISPOA). Brasília, 1974. p.138-209.

COSTA, E. O.; MELVILLE, P. A.;RIBEIRO, A. R.;WATANABE, E. T. Estudo da etiologia das mastites bovinas nas sete principais bacias leiteiras do Estado de São Paulo. Revista Napgama, São Paulo, n. 4, p. 6-13, 2000.

COSTA, E. O.; MELVILLE, P. A.;PRADA, M. S.; CARCIOFI, A. C.;RIBEIRO, A. R.; PANTANO, T. . Influência do manejo de ordenha com a participação do bezerro sobre a ocorrência de mastite. Revista Brasileira de Medicina Veterinária, Brasil, v. 19, n. 1, p. 19-22, 1997.

CRUZ, F.E.R., CARNEIRO, P.R., CAVALCANTE, S.S. Alguns fatores econômicos e sociais dos agricultores do município de lgarapé-MG. Arquivo Brasileiro de Medicina Veterinária e Zootecnia, Belo Horizonte, v. 33, n. 3, p. 575-584, 1981.

ESCOSTEGUY, C. DAMBORIARENA, E.; FREITAS, P. A produção de leite como alternativa para os pequenos produtores. Textos para discussão, Departamento de Economia e Contabilidade, UNIJUÍ. IjuíRS, 1993.

FASSIO, L.H.; REIS, R.P.; GERALDO, L.G. Desempenho técnico e econômico da atividade leiteira em Minas Gerais. Ciência e Agrotecnologia, Lavras, v. 30, n. 6, p. 1154-1161, 2006.

FURLONG, J.; MARTINS, J.R.S. Resistência dos carrapatos aos carrapaticidas. Juiz de Fora: CNPGL-EMBRAPA, 2000. 25 p. (Boletim Técnico 59).

IBGE. Censo agropecuário: 1995/1996. Rio de Janeiro. Disponível em: <http://www.ibge.gov.br/home/estatistica/economia/agropecuária/ censoagro/default.shtm. Acesso em: 20 out. 2004.

ICMSF - International Comission Microbial Sacrifications for Food Microorganisms in Food I. Their significance and method of inumeration. 2 ed. Toronto, p. 433, 1980.

Instituto Nacional de Colonização e Reforma Agrária - INCRA. Novo retrato da agricultura familiar - o Brasil redescoberto. Projeto de Cooperação Técnica INCRA/FAO. Brasília. Fev, 2000. Site: http:// www.incra.gov.br/fao/ (18 jul. 2005)

JESUS, M.H.; SANAVRIA, A.; CAMPOS, F.C.;PEREIRA, C.R.;PRAXEDES, C.S. Perfil higiênico sanitário do Mutirão Eldorado em Itaguaí/RJ. In: VII Seminário Bienal de Pesquisa da UFRRJ 1995, Anais... p. 111, 1995.

LEITE, R.C.; LIMA, J.D.Fatores sanitários que influenciam na criação de bezerros. Arquivo da Escola de Veterinária da UFMG, Belo Horizonte, v. 34, n. 3, p. 485-492, 1982.

LEITE, R. C. Boophilus microplus (Canestrini, 1887): Susceptibilidade, uso atual e retrospectivo de carrapaticidas em propriedades das regiões fisiográficas da baixada do Grande Rio e Rio de Janeiro: Uma abordagem epidemiológica. 1988. 122 p. Tese (Doutorado em Parasitologia Veterinária), Universidade Federal Rural do Rio de Janeiro. Itaguaí.1988.

LEITE, R.C.; ROCHA, C.M.B.M. Contagens de carrapatos em bovinos no momento do banho carrapaticida em rebanhos leiteiros do Município de Divinópolis/ MG. Arquivo Brasileiro de Medicina Veterinária e Zootecnia, Belo Horizonte, v. 51, n. 1, p. 41-42, 1999.

LEITE, R.H.M.;LAGE, A.P.; JAYME, V.S. MODENA, C.M. Perfil produtivosanitário de propriedades produtoras de bovinos do estado da Paraíba, Brasil, 2000. Ciência Animal Brasileira, Goiânia, v. 5, n. 4, p. 199-209, 2004.

LIMA, J.P.; LIMA, M.C.; PESSOA, T.D.; COSTA, M.C.O. Levantamento das diferenças sócio-econômicas em propriedades leiteiras no Vale do Paraíba -SP. In: XXIX Congresso Brasileiro de Medicina Veterinária, Anais... Gramado RS, 2002.

MARQUES, V.M.; REIS, R.P.; SÁFADI, T.; REIS, A.J.. Custos e escala na pecuária leiteira: estudo de casos em Minas Gerais. Ciência e Agrotecnologia., Lavras. v. 26, n. 5, p. 1027-1034, 2002.
MOREIRA, F. X. Condições sanitárias e estrutura de produção na bovino cultura dos núcleos de João Pinheiro e Rio Verde no Estado de Minas Gerais. Belo Horizonte: Escola de Vet, UFMG. Tese de Mestrado em Medicina Veterinária, p. 92, 1988.

PHILPOT. W. N.; E. S.C.; NICKERSON. Mastitis: Counter attack. a strategy to combat mastitis. Babson Bros. Co., Naperville, Illinois, USA., 1991. BRASIL, Ministério da Agricultura, Pecuária e Abastecimento. Programa Nacional de Controle e Erradicação da Brucelose e da Tuberculose - PNCEBT, 2001.

PRONAF.Site: http://www.pronaf.gov.br/quem_somos/perguntas.htm (4 maio 2007)

PRADO, E.; CRUZ, F.E.R.; VIANA, F.C.; TORRES, A.M.C.; Problemas sanitários do rebanho de leite: percepção dos criadores. Arquivo Brasileiro de Medicina Veterinária e Zootecnia, Belo Horizonte, v. 49, n. 1, p. 19-29, 1997.

RADOSTITS, O.M.; GAY, C.C.;BLOOD, D.C.; HINCHCLIFF, K.W. Clínica Veterinária, 9. ed., Rio de Janeiro: Guanabara Koogan, 2002, p. 56-59.

REIS, R. P. Estrutura produtiva da pecuária leiteira sob condições de intervenção: um estudo de caso em Minas Gerais. 1992. 151 p. Tese (Doutorado em Economia Rural) - Universidade Federal de Viçosa, Viçosa, MG.

REIS, J.C.G.; SILVA, V.; AMARAL, A.M.P.; CAMARGOS, A.M.M.P. Evolução na eficiência produtiva da pecuária leiteira em pequenos e médios estabelecimentos paulistas. Agricultura São Paulo, São Paulo, v. 53, n. 2, p. 85-96, 2006.

ROCHA, C.M.B.M. Caracterização da percepção dos produtores de leite do município de Divinópolis/MG sobre a importância do carrapato Boophilus microplus e fatores determinantes das formas de combate utilizadas. 1995. 205 f. Dissertacão (Mestrado em Medicina veterinária preventiva e Epidemiologia)-Curso de pós-graduação em Medicina Veterinária, Universidade Federal de Minas Gerais, 1995.

ROCHA, C.M.B.M.; OLIVEIRA, P.R.; LEITE, R.C.; CARDOSO, D.L.; CALIC, S.B.; FURLONG, J. Percepção dos produtores de leite do município de Passos, MG, sobre o carrapato Boophilus microplus (Acari: Ixodidae), 2001. Ciência Rural, Santa Maria, RS, v. 36, n. 4 p. 1235-1242, 2006. ROCHA, C.M.B.M.; GOMES, G.S. indicadores de produção relacionados com levantamento sanitário em rebanhos do núcleo Jersey Fernão Dias, no Município de Lavras/MG, 1997. Ciência e Agrotecnologia, Lavras, v. 23, n. 4, p. 938-947, 1999.

ROLDÃO, C.D.R.; SOUZA, M.M.O.; FRANCIS, D.G.; PEREIRA, W.A.B.; SANTOS, R.A.V.; SILVA,M.C. A produção de leite em assentamentos de reforma agrária: uma alternativa para a subsistência de produtores familiares. In: XXIX Congresso Brasileiro de Medicina Veterinária. Anais... Gramado, RS, 2002.

SCHNEIDER, S. Teoria Social, Agricultura Familiar e Pluriatividade. Revista Brasileira de Ciências Sociais, São Paulo, v. 18, n. 51, p. 99120, 2003.

SERVIÇO de Apoio às Micro e Pequenas Empresas de Minas Gerais. Federação da Agricultura do Estado de Minas Gerais. Relatório da pecuária leiteira do Estado de Minas Gerais. Belo Horizonte, 1996. 2 v. $212 \mathrm{p}$.

SILVA, T.F.; SILVA, R.A; BOTTEON, R. C. C. M.; BOTTEON, T.P.L.; OLIVEIRA, B.C.R.S.; ROIER, E.C.R. Fatores de manejo relacionados à ocorrência de mastite na região Sul Fluminense. A Hora Veterinária, v. 141,2004

SMITH, B.P. Tratado de medicina interna de grandes animais. São Paulo: Manole, 1993.

TOKARNIA, C.H.; DOBEREINER, J.; PEIXOTO, P.V. Deficiências minerais em animais de fazenda, principalmente bovinos em regime de campo. Pesquisa Veterinária Brasileira, Rio de Janeiro, v. 20, n. 3, 2000.

VIANA, F.C.; CRUZ, F.E.R.; LAENDER, F.C. Diagnóstico da situação de produção bovina de leite do município de sete Lagoas-MG. Arquivo Brasileiro de Medicina Veterinária e Zootecnia, Belo Horizonte, v. 39, n. 5, p. 699-717, 1987.

Vieira, L.C.; Veiga, J.B.; Freitas, C.M.K. Qualidade do Leite nas Propriedades do Município de Uruará, Pará. Comunicado Técnico n. 69. Ministério da Agricultura, Pecuária e Abastecimento, 2002. 